\title{
GIS-Based Urbanization Prediction Model Considering Neighborhood Relationship of the Unit of the "Block" in the Outskirts of Metropolitan Area
}

\author{
Kayoko Yamamoto \\ Graduate School of Information Systems, University of Electro-Communications, Tokyo, Japan \\ Email: k-yamamoto@is.uec.ac.jp
}

Received 12 June 2014; revised 8 July 2014; accepted 1 August 2014

Copyright (C) 2014 by author and Scientific Research Publishing Inc.

This work is licensed under the Creative Commons Attribution International License (CC BY).

http://creativecommons.org/licenses/by/4.0/

(c) (i) Open Access

\section{Abstract}

On the outskirts of the metropolitan areas in Japan, the rapid development of urban areas and the improvement in transportation networks have brought various land use problems in their wake, including urban diffusion and the phenomenon of urban sprawl. There is a strong need for accurate predictions of land-use change and future urbanization, as well as investigation of the appropriateness of present land use controls and the land use controls that will be required in the future. This study took as its object the outskirts of the Keihanshin (Kyoto-Osaka-Kobe) Metropolitan Area, the second largest conurbation in Japan after the Tokyo Metropolitan Area, and used the digital maps and spatial analysis offered by GIS. It aimed to: 1) describe the characteristics of land use controls, land use and urbanization; 2) develop an urbanization prediction model that considers the neighboring relationship of neighboring areas on a $100 \mathrm{~m}$ mesh unit; 3) apply this model to the study area and verify its validity regarding the conditions of present land use; 4) compare urbanization prediction results by this model with the present land use controls; and 5) make predictions for future urbanization and propose remedial measures for future land use controls.

\section{Keywords}

Urbanization Prediction Model, Neighborhood Relationship, Urban Diffusion, Urban Sprawl, Land Use Controls

\section{Introduction}

The lower cost of land in the outskirts of metropolitan areas in comparison with central metropolitan areas in

How to cite this paper: Yamamoto, K. (2014) GIS-Based Urbanization Prediction Model Considering Neighborhood Relationship of the Unit of the "Block" in the Outskirts of Metropolitan Area. Journal of Geographic Information System, 6, 330-344. http://dx.doi.org/10.4236/igis.2014.64030 
Japan has meant that it has been comparatively easy to secure ground in these areas on which to construct offices and residences. Moreover, improvements in transportation networks in recent years have led to an improvement in accessibility to central metropolitan areas, which has encouraged the proliferation of urban areas on the outskirts of metropolitan areas. In many cases such urban areas have developed with extreme rapidity, and this has led to problems in land use such as urban diffusion and the phenomenon known as urban sprawl.

This has meant an exacerbation of problems related to competition between uses to which land is put, for example between urban areas, farmlands and forests, as well as the co-existence of these different types of land, long pointed out as a theme in land use plans. On the outskirts of the metropolitan areas, there is a disconformity between land use controls and actual land use, and this disconformity will only increase with the advance of urbanization. The need for land use adjustment is urgent. It is thus essential to get an exact picture of the actual state of land use in a region in its entirety and verify whether appropriate land use controls have been implemented. It is also essential that we try to predict changes in land use that are likely to occur and the direction that is likely to be taken by future urbanization, examine whether the present land use controls are appropriate, and propose the kind of land use controls that will be required.

This study took as its object the outskirts of the Keihanshin (Kyoto-Osaka-Kobe) Metropolitan Area, the second largest conurbation in Japan after the Tokyo Metropolitan Area. Based on its findings with regards to trends in urbanization, it aimed to: 1) develop an urbanization prediction model that takes into account the correlation of neighboring areas on a $100 \mathrm{~m}$ mesh unit; 2) apply this model to the study area and verify its validity for present land use; 3) compare urbanization prediction results by this model with the present land use controls; and 4) make predictions for future urbanization and propose remedial measures for land use controls.

A fair amount of accumulated research has been achieved regarding methods for predicting land-use change and future urbanization, mainly in the field of city planning. The main methods used have included the transition probability model and cellular automaton model. The former focuses on the land use composition of the entire study area, while the latter considers the influence of land use situations in environing areas mainly using a 500 m mesh unit. However, little use has been made of GIS with either of these models, and no account has been taken of the neighboring relationship of land use between neighboring areas using small area units. On the basis of methods offered by previous studies, this study aims to use the digital maps and spatial analysis offered by GIS to develop an urbanization prediction model that can reflect the mutual influence and neighboring relationship of land use in neighboring areas using the unit of the block (in Japanese, gaiku, literally city or town block).

\section{Problems of the Land Use Controls in the Study Area and Related Work}

In Japan, city planning area is specified per substantial city zone in which city planning should be defined based on the New City Planning Act in 1968. In the entire city planning area, in order to prevent disorderly urbanization and perform suitable land use in each area, the land use plan is defined and land use controls are carried out for every area respectively. The city planning areas in Japan are divided into the zoning areas (the Urbanization Promotion Area and the Urbanization Control Area), and the area Outside of the Zoning Area. In the three kinds of areas within the city planning area, as mentioned later, land use controls are defined and carried out individually.

There are twelve kinds of land use districts for residential, commercial and industrial uses specified within the city planning area. For the Urbanization Promotion Areas, the Use Districts are specified for the whole area. In the Urbanization Control Areas, and Outside the Zoning Area, however, land use districts are specified only for some areas, with the land use control of such districts conforming to that of Urbanization Promotion Area. The area Outside the Zoning Area, with the exception of the Use District, is called the White Area. In principle, except for the Urbanization Promotion area, development should not be permitted in other areas.

In the Urbanization Control Areas and the White Areas, the land use controls are examined from the perspective of a rapid, disorderly urbanization process accompanying the random development of natural environmental resources. The restrictions to development activities, however, differ in the Urbanization Control Area and the White Area. Although any development activity is restricted in order to limit urbanization in the Urbanization Control Area, development in more than $3000 \mathrm{~m}^{2}$ of the White Area is restricted to preserve the environment, farmlands and forests in the area. Since the Urbanization Control Area is specified to adjoin the Urbanization Promotion Area and urbanization pressure is very heavy, its restriction to development is especially severe.

Yamamoto (1999) [1], and Yamamoto and Nakamura (2000) [2] showed the land uses and land use transfor- 
mations accompanying regional development for the past thirty years have been determined. Yamamoto (2001, 2002, 2003a and 2003b) [3]-[6], and Yamamoto and Nakamura (2004) [7] pointed out that land use problems accompanying urbanization have arisen in Shiga Prefecture specifically in city planning areas. However, Yamamoto (2001, 2002 and 2003a) [3]-[5] also pointed out that urbanization had not significantly advanced outside the city planning area in the Lake Biwa watershed (Shiga Prefecture). Thus, from the perspective of agricultural environment, only the land use problems especially in the Urbanization Control Areas and the White Areas inside the city planning area are examined in this study. Among the land use systems of Japan, the city planning system has the most important role in the land use control in Shiga Prefecture. Furthermore, based on the above-mentioned studies, considering the regional characteristics, Yamamoto (2005) [8] developed an urbanization prediction model in Shiga Prefecture.

\section{Method}

\subsection{Framework and Method}

Section 4 introduces how to develop an urbanization prediction model that takes into consideration the situation of the land use and the urbanization of Shiga Prefecture, based on the results of the above-mentioned precedence studies. Section 5 describes the characteristics of land use controls, land use and urbanization in Shiga Prefecture. Section 6 explains how to conduct an urbanization prediction for 1994 based on land use data taken in 1965, and then examined the validity of the model in comparison with land use data taken in 1994. Section 6 also explains how to perform a future urbanization prediction for after 1994 based on land use data taken in 1994.

On the basis of these prediction results, Section 7 describes how to apply the urbanization prediction model developed in this study to make an evaluation of land use controls, mainly those in city planning areas. In this study, in order to offer information to aid policy judgments pertaining to the Lake Biwa Comprehensive Conservation Plan (LBCCP; Mother Lake 21 Plan, 1999-) on the basis of findings, the analysis results are shown for the seven sub-basin units that are the regional classification as shown on maps for the LBCCP (Shiga Prefecture, 2000) [9].

\subsection{Study Area Description}

The area for this study was Shiga Prefecture, located as shown in Figure 1 in the central part of the main island of Honshu. The first distinctive feature of this area is that it contains Lake Biwa, the largest lake in Japan, in the center of the prefecture; the reduction of the environmental load on Lake Biwa is thus an important policy issue. Lake Biwa, the largest lake in Japan (with a water volume of 27.5 billion $\mathrm{m}^{3}$ ), provides water to a population of 14 million people in Shiga, Osaka, Kyoto and Hyogo Prefectures. Shiga Prefecture, a marginal region of a metropolitan area, underwent a land use transformation as a result of rapid urbanization, as well as a variety of regional development plans such as the Lake Biwa Comprehensive Development Plan (LBCDP, 1972-1997).

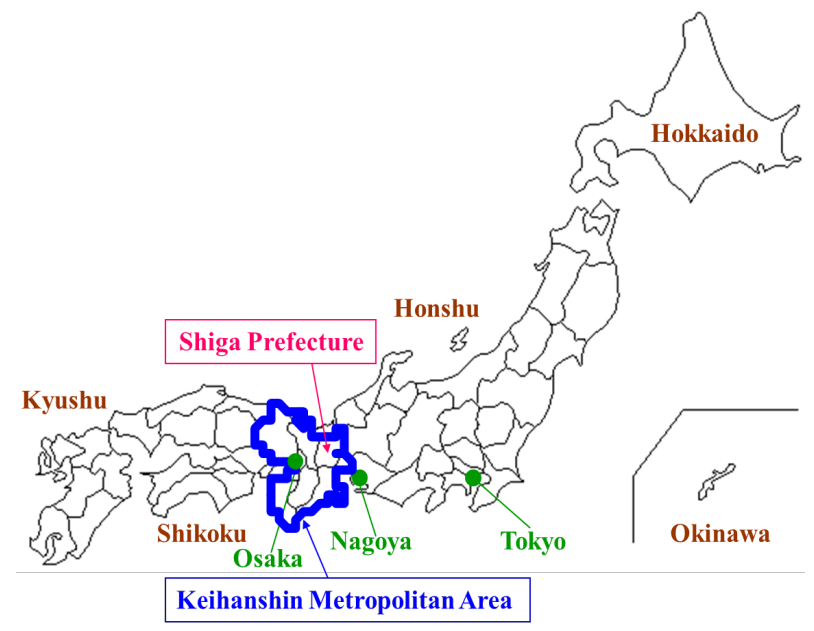

Figure 1. Location of Shiga Prefecture in Japan. 
The second distinctive feature is the remarkable advance of urbanization, due to the location of this area on the outskirts of the Keihanshin metropolitan area: urbanization has occurred mainly in the southern lakeshore region where time distance to Osaka (the central city of the Keihanshin metropolitan area) is about an hour. Ever since the region was specified as an urban development zone, "the eastern Lake Biwa area", in the Kinki Bloc Development Act in 1963, it has played the role of receptacle for easing the over-concentration of population and industries in the central parts of the Keihanshin metropolitan area.

The third distinctive feature is the tremendous changes in land use that have occurred centering on the lakeshore region over the past roughly 30 years, due to the LBCDP and the implementation of land development for recreational uses under the planning scheme called the Resort Necklace Plan (RNP, 1987-). Particularly due to the LBCDP, on the coastal fringe lands of Lake Biwa, factors contributing to the loss of natural coastline around the lake over the past decades included construction of a round-the-lake flood control levy, two-lane road, paddy-land reforms, with installation of an irrigation pipeline outlet to individual paddies and outflow water flowing directly to the lake (in contrast to the traditional practice of constructing paddies in series, with the outflow water from one paddy flowing into the next paddy. The loss of ecological integrity along the lakeshore land is said to have significantly contributed to the deterioration of the water quality of Lake Biwa, because of the loss of the natural buffering capacity of the lakeshore ecosystem.

\subsection{Sub-Basin Units in the Study Area}

During the last phase of the LBCDP, the Shiga Prefectural government began to consider how comprehensive conservation of the lake could be assured for future generations. The resulting the LBCCP was inaugurated in October 1999 (Shiga Prefecture, 2000). The seven watershed sub-basin units are illustrated in Figure 2. Implementing integrated watershed management requires examination of the land use controls in the sub-basin units, ignoring the administrative boundaries. It also is essential to re-consider the proper designation of land uses needed to reduce the pollutant loads to Lake Biwa, and to determine whether or not there are any unpredicted pollutant loads reaching the lake. Focusing on the relationship between the land use plan and the environmental conservation and management plan, land use controls are analyzed by classifying the watershed into seven regions, based on the sub-basin units of the LBCCP (see Figure 2). Considering regional characteristics such as topographic and geographic conditions, locations and traffic conditions, the seven basin units were organized into 4 types as follows:

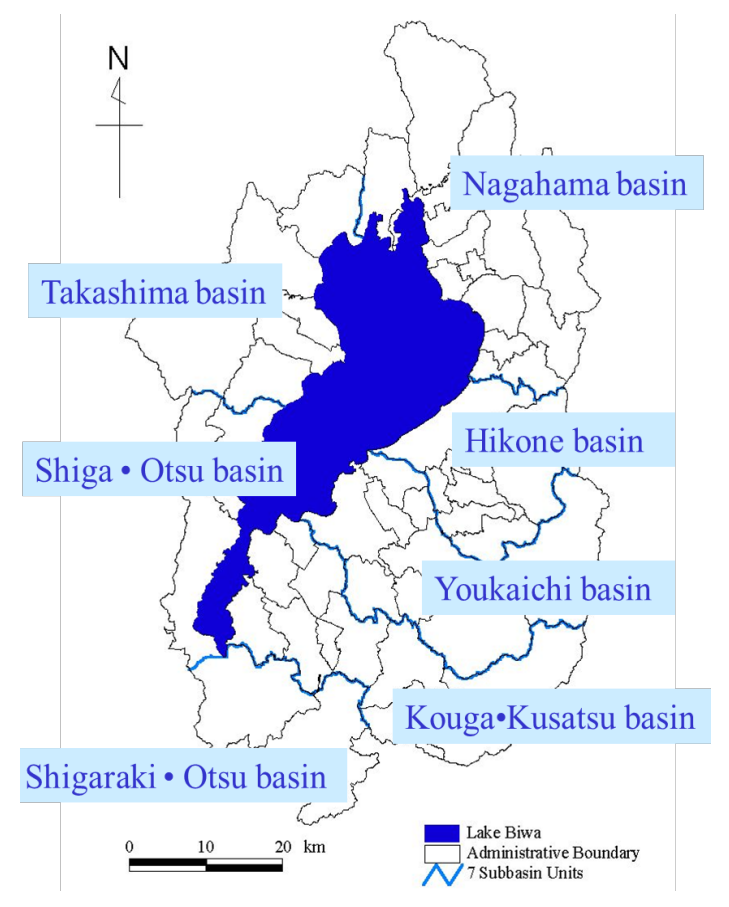

Figure 2. Seven sub-basin units in Shiga Prefecture. 
- Type 1: The area in the southeastern plain part of the watershed, in which urbanization is increasing. It includes two southeastern basins (Kouga·Kusatsu and Youkaichi);

- Type 2: The area distant from the Keihanshin metropolitan area, which forms independent small-scale city zones. It includes two northeastern basins (Hikone and Nagahama);

- Type 3: The rural area, in which urbanization has not encroached; namely, the northwestern basin (Takashima);

- Type 4: The area contiguous to the Keihanshin metropolitan area. It includes two southwestern basins (Shigaraki·Otsu and Shiga·Otsu).

\section{Development of an Urbanization Prediction Model}

\subsection{Creating a GIS Database}

In this study, the aim was to develop an urbanization prediction model to treat the diffusion phenomenon of urban areas using the small-scale unit of the block, paying attention to the fact that urbanization had advanced especially in the environs of the old urban areas in the past 30 years (from 1965 to 1994) in Shiga Prefecture. The GIS used in this analysis were Arc GIS ver10.0 and Arc View ver3.2 which are developed by ESRI Inc., using a GIS database developed for the LBCCP in Shiga Prefecture. Specifically, data pertaining to land use (as of 1965 and 1994), land use control and administrative boundary were used in this study. Moreover, with the objective of efficiency of data management, GIS was used to process these digital data to a $100 \mathrm{~m}$ mesh unit on a spatial scale on the level of the block (for a total of 407,318 meshes in Shiga Prefecture) in order to use them for the analysis after Section 4.

\subsection{Configuring a Transition Rule for Urbanization and Land Use Conversion}

Firstly, a transition rule had to be configured that would determine whether the meshes where land that had uses other than urban areas, for example paddy fields, dry fields and forests, in t term (1965) had under the influence of urbanization in neighboring areas in $t+1$ term (1994) been converted into urban areas or remained in the original land use. Regarding the conditions for neighboring relationship on the level of the block, as shown in Figure 3, consideration was given first to the proportion held by an urban area in a particular neighbor area of a nine-mesh unit (the main mesh in question and the eight meshes surrounding it). The proportions of various land uses were then computed for every nine-mesh unit, and where the proportion of one kind of land use was overwhelmingly large, the set-up was configured so that the entire nine-mesh unit could be converted to that land use. In addition, since based on this rule there were some meshes that had been urban area in the t term (1965) but appeared to have been converted to other land uses, they were extracted after the series of operations and corrected so that they could remain as urban areas.

Moreover, if in the nine-mesh unit urban areas and other land use occupied a major proportion and were equal to each other in number, all the areas of the nine-mesh unit were converted into urban areas. The reason for this is that when conducting urbanization prediction based on land use data in 1965, the distribution of urban area is closer to the actual conditions in 1994 when it is presupposed that all the areas of a nine-mesh unit are converted into urban areas than when it is presupposed that no land use changes at all have taken place. The same transition rule applied in this study also for the period between $t+1$ term (1994) and $t+2$ term (2023). Since these 30 years are basically consistent with the period for LBCCP (2000-2020), by performing an urbanization prediction for this period we can provide information that pertains not only to the land use plans but also to this environmental plan.

\section{Characteristics of Land Use Controls, Land Use and Urbanization}

\subsection{Land Use Controls}

The city planning area was established in the 1960s as one of urban development zones in the Kinki bloc. Shown in Figure 4, the Urbanization Promotion Area is 6.4\% of the total Shiga Prefecture, the Use District distributed throughout the city planning area is $6.9 \%$, the Urbanization Control Area is $36.6 \%$, the area Outside the Zoning Area is $14.7 \%$, the White Area (the outside portion of the Zoning Area, with the exception of the Use District) is $14.2 \%$, and the area Outside of the City Planning Area is $42.3 \%$. Figure 5 displays the land use con- 


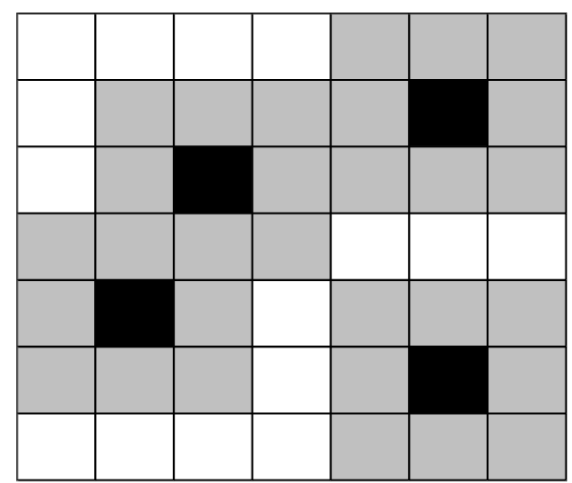

Main mesh area

Neighboring meshes

( 8 meshes that surround main mesh area)

Figure 3. Cnonditions for neighboring relstionship of the block.

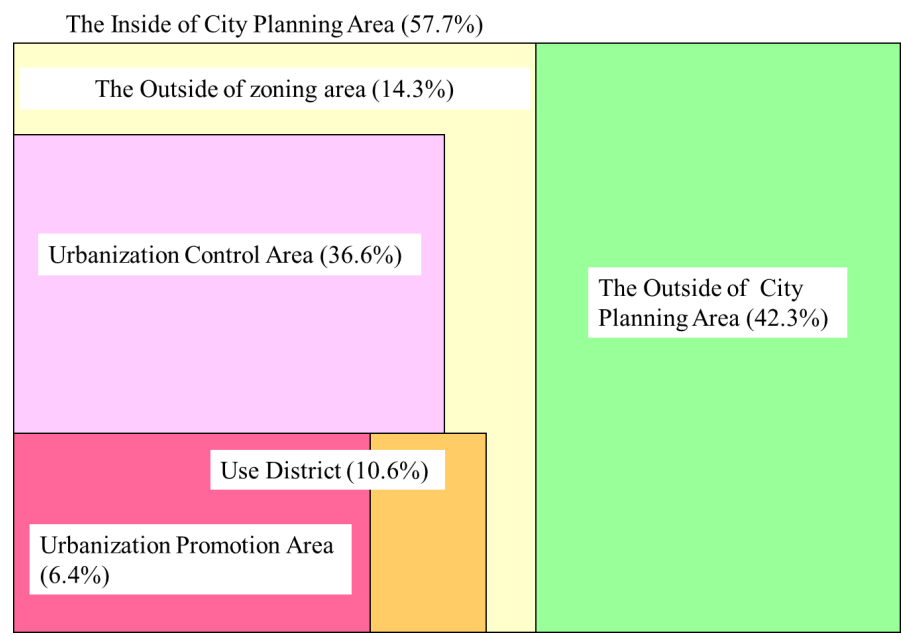

Figure 4. Specified areas of land use control in Shiga Prefecture.

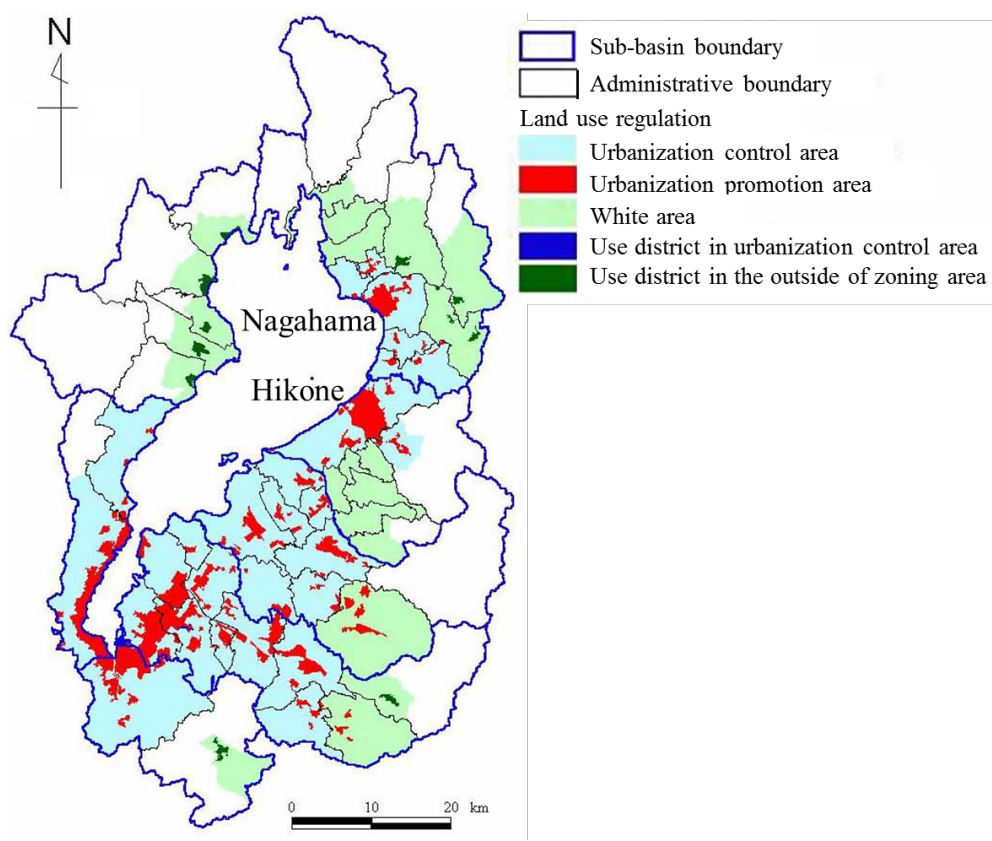

Figure 5. Land use controls in Shiga Prefecture. 
trol in Shiga Prefecture. From Figure 5, it can be seen that the Urbanization Promotion Areas are located in the southern lakefront region, the inland areas of the eastern part, and the circumference areas of both Hikone city and Nagahama city. The Urbanization Control Areas are specified around the Urbanization Promotion Area, and the White Areas spread out around these two kinds of areas. In the six small-scale towns in the northwestern part of the area under study, however, no area was designated as an urbanization promotion area. For these areas this study therefore decided to consider land use district as the same as urbanization promotion area. After Section 5 therefore an analysis of land use districts was carried out.

\subsection{Comparison of the Land Uses in 1965 and 1994}

Figure 6 shows a comparison of the land uses in 1965 and 1994 of Shiga Prefecture while Table 1 shows the changes in land use in Shiga Prefecture for the past 30 years, based on the GIS data of the land uses in both 1965 and 1994. In the present study, the urban areas which were already formed in 1965 are referred to as "old urban areas", and the urban areas which have newly formed over the past 30 years (1965-1994) are referred to as "new urban areas", We can see from Figure 6 that new urban areas have increased for the most part in the southern and the southeastern parts. Moreover, the conditions of transformation in land use to urban areas shown in Table 1 shows that the proportion of urban areas has increased by $3.4 \%$ in the past 30 years throughout Shiga Prefecture. Among the new urban areas, the areas that have been converted from farmlands (mainly paddy fields and dry fields) occupy $2.3 \%$ and the ones have been converted from forests occupy $1.2 \%$. It has already been pointed out by Yamamoto (2001, 2002 and 2003b) [4] [5] [7] that the new urban areas converted from farmlands have expanded mainly around the old urban areas in the plains that stretch from southern regions across to the east in the lakeshore region. In contrast, in the southern inland areas, the new areas converted from the forests have increased alongside the main roads.

\subsection{Urbanization}

Figure 7 provides the characteristics of urbanization in each of the seven sub-basin units for the past thirty years. In this study, the urban area that already existed in 1965 is referred to as the "old urban area", and the one newly formed over the past thirty years (1965-1994) is referred to as "new urban area". The old urban area constitutes the major proportion and is distributed mostly along the railway line and main roads in the entire Shiga Prefecture. Two northeastern basins (Hikone basin and Nagahama basin) and northwestern basin (Takashima basin) have the highest ratios of old urban areas (more than 65\%), because these three basins are distant from the Keihanshin metropolis, and the populations have increased only slightly over the past several decades.

The Land use conversion to urban areas is also included in Figure 7. Although many of the new urban areas have been converted from farmland in the lakefront regions, the ones that have been converted from forests mostly lie in the circumference areas of the railway and main roads in the southern inland region. Except for the one of northeastern basins (Nagahama basin), the new urban areas converted from farmland occupy about 30\% in the other six basins. On the other hand, in two southwestern basins (Shigaraki-Otsu basin and Shiga-Otsu basin) with a lot of forest areas, the new urban areas converted from forests occupy about $20 \%$. Thus, it is confirmed that there is a marked difference in urbanization in each of the seven basins.

\section{Analysis and Discussion of Urbanization Prediction Result}

\subsection{Urbanization Prediction Result}

Urbanization prediction for 1994 was performed based on land use data in 1965, and the predictive values were computed by comparing them with the land use data in 1994. Figure 8 shows the predictive values of each municipality, and Figure 9 shows the urbanization prediction results compared with the actual distribution of the urban areas in 1994. In each municipality, each kind of specified areas of land use control and Shiga Prefecture in its entirety, the predictive values were calculated dividing the numbers of $100 \mathrm{~m}$ mesh for predicted urban area in 1994 (see Figure 9) by the ones for real urban area in 1994.

The predictive value of the urbanization prediction model developed in this study was found to be $58.7 \%$ for Shiga Prefecture in its entirety. The predictive values are as high as $67.7 \%$ and $69.2 \%$ respectively in the white areas and areas outside city planning areas where there is little possibility for the advancement of urbanization. On the other hand, the predictive value is $57.8 \%$ in urbanization promotion areas and land use districts, and $54.4 \%$ 


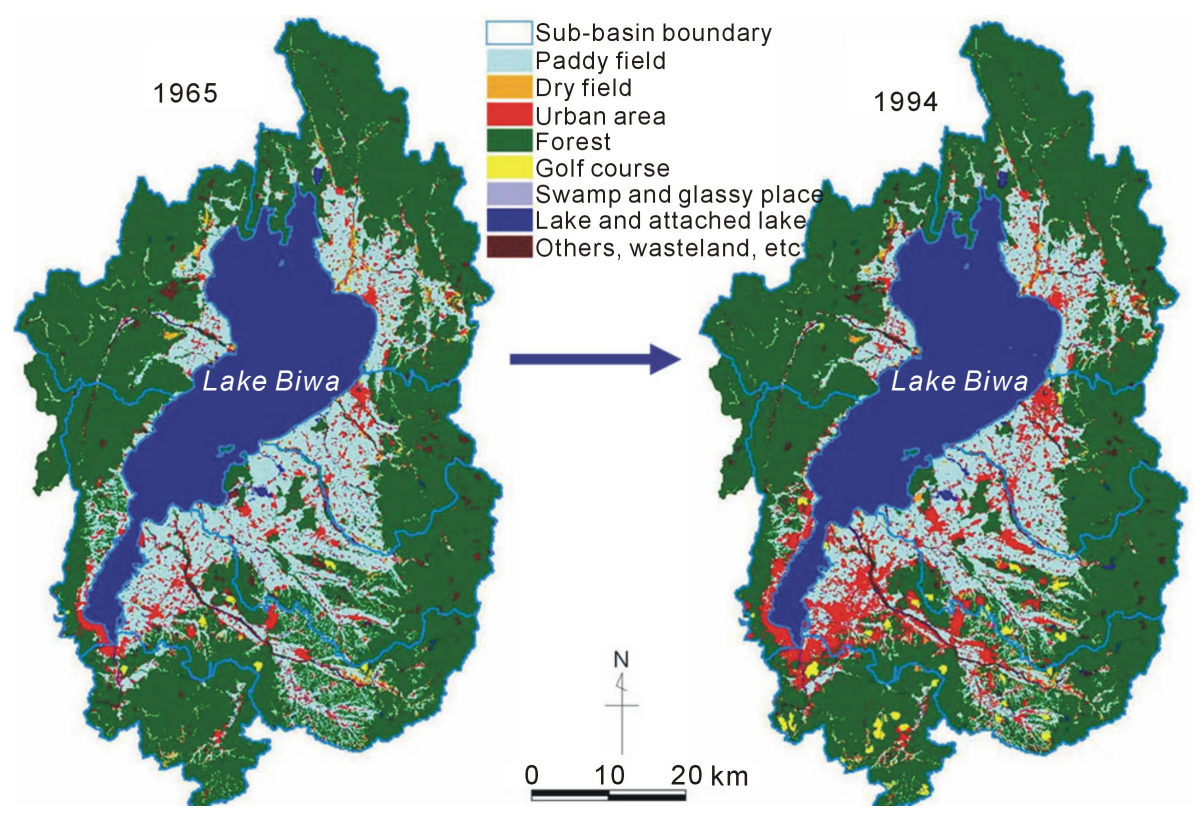

Figure 6. Land use in Shiga Prefecture $(1965,1994)$.

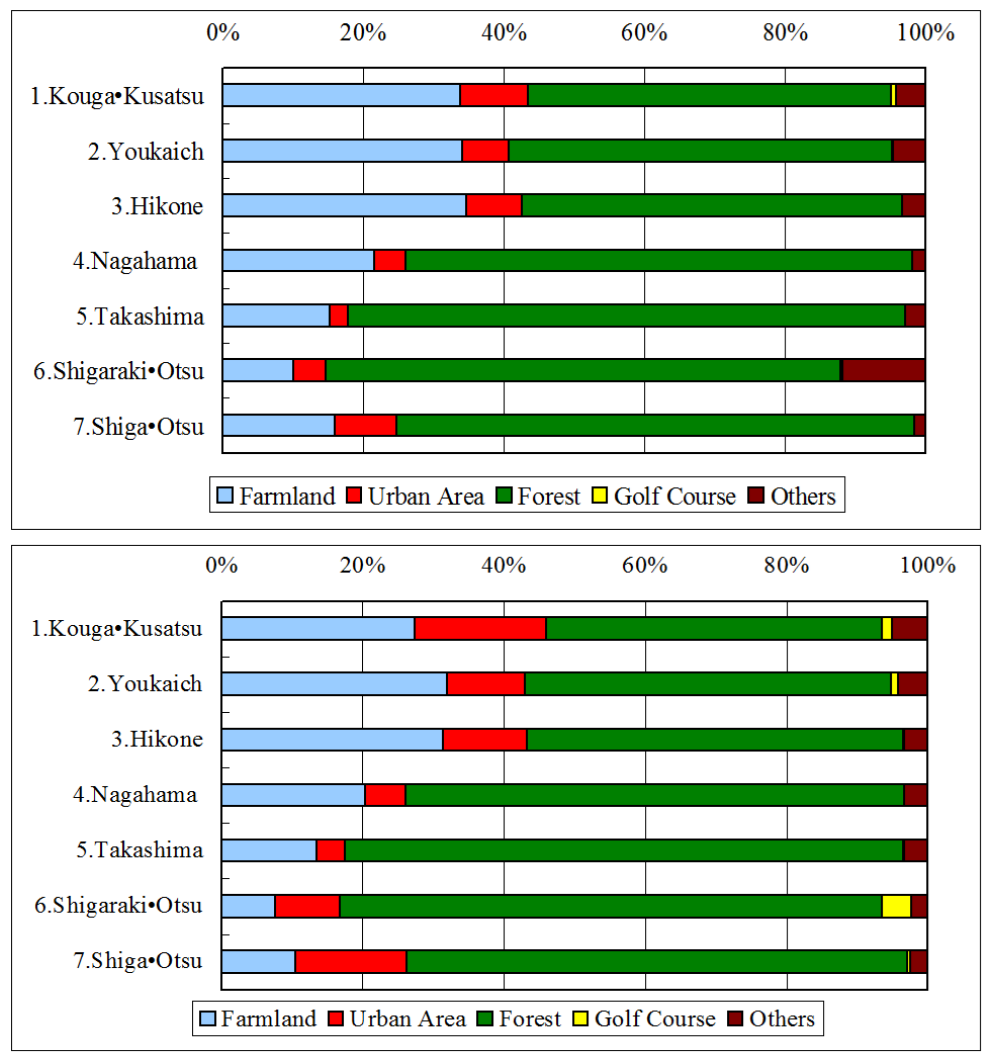

Figure 7. Land use in seven sub-basin unit $(1965,1994)$.

in urbanization control areas. Moreover, as shown in Figure 8, the predictive values are low in areas in the south that have shown an especially remarkable increase in urban areas over the past 30 years. The predictive values are high especially in the northeastern and northwestern areas which have not seen any particular transformation in land use. 
Table 1. Land use transformation using 100 m mesh unit (1965-1994).

\begin{tabular}{ccccccccc}
\hline & Paddy field & Dry field & $\begin{array}{c}\text { Urban } \\
\text { area }\end{array}$ & Forest & Golf course & $\begin{array}{c}\text { Swamp and } \\
\text { glassy place }\end{array}$ & $\begin{array}{c}\text { Lake and } \\
\text { attached lake }\end{array}$ & $\begin{array}{c}\text { Others, } \\
\text { wasteland, etc. }\end{array}$ \\
\hline Paddy field & 16.3 & 0.1 & 0.1 & 0.3 & 0.0 & 0.0 & 0.0 & 0.1 \\
Dry field & 0.2 & 0.7 & 0.0 & 0.2 & 0.0 & 0.0 & 0.0 & 0.1 \\
Urban area & 2.2 & 0.1 & 4.9 & 1.2 & 0.0 & 0.0 & 0.1 & 0.2 \\
Forest & 0.4 & 0.1 & 0.1 & 52.7 & 0.0 & 0.0 & 0.0 & 0.3 \\
Golf course & 0.1 & 0.0 & 0.0 & 0.5 & 0.1 & 0.0 & 0.0 & 0.0 \\
Swamp and glassy place & 0.0 & 0.0 & 0.0 & 0.0 & 0.0 & 0.0 & 0.0 & 0.0 \\
Lake and attached lake & 0.1 & 0.0 & 0.0 & 0.0 & 0.0 & 0.0 & 17.0 & 0.1 \\
Others, wasteland, etc. & 0.3 & 0.0 & 0.0 & 0.4 & 0.0 & 0.0 & 0.1 & 1.0 \\
Land use (1965) & 19.5 & 1.0 & 5.1 & 55.3 & 0.1 & 0.1 & 17.2 & 1.6 \\
Land use (1994) & 16.9 & 1.2 & 8.5 & 53.6 & 0.7 & 0.1 & 17.2 & 1.8 \\
\hline
\end{tabular}

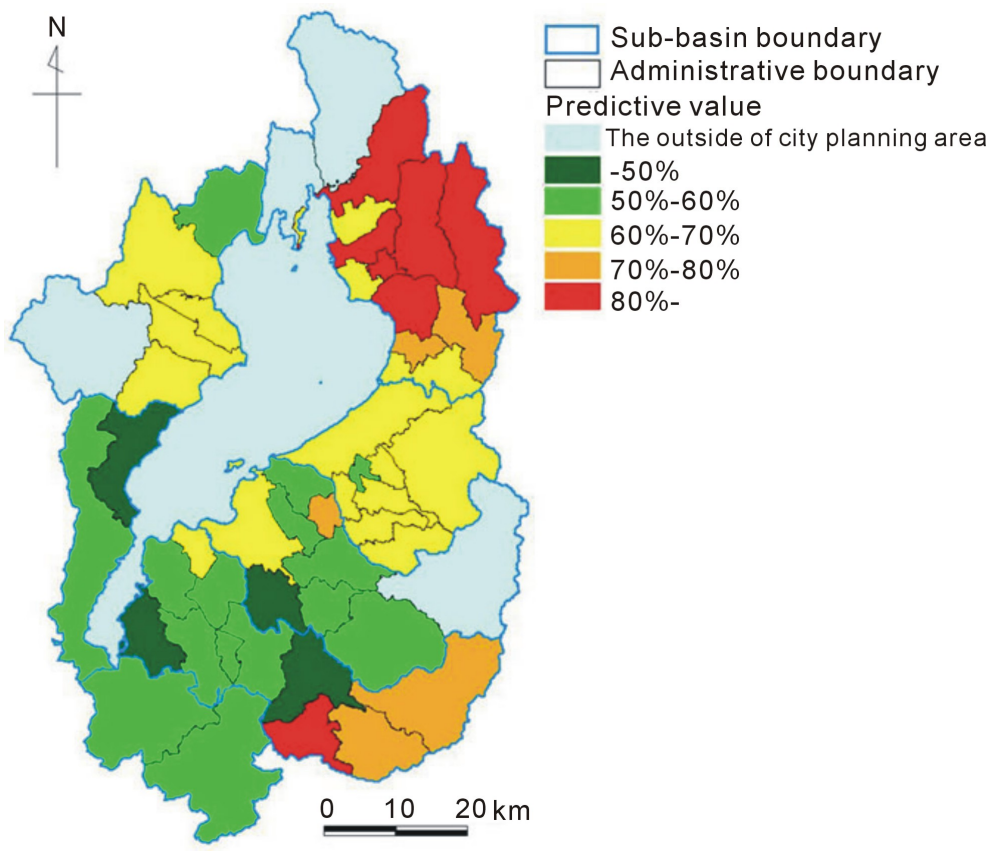

Figure 8. Predictive values in each municipal.

Figure 9 shows the situation in Shiga Prefecture in more detail, and as we can see from this there is the most remarkable difference between the prediction results and the distribution of the urban areas in 1994 in the city of Kusatsu and its neighboring municipalities, where in recent years there has been advance in the construction of new towns and the accumulation of cultural facilities such as universities and libraries. The difference between the prediction result and the actual distribution of the urban areas in 1994 is also conspicuous in the western lakeshore region in Otsu city and in the southern inland area. These areas have lately seen brisk new towns development and housing development.

Figure 10 shows a part of new towns in Kusatsu city, high density urban areas in Otsu city and farm village in Koura Town. In the city of Kusatsu and its neighboring municipalities, farmlands in particular were converted into urban areas in urbanization control areas on the lakeshore. In the western lakeshore region Otsu city, since the plain part is tremendously narrow, forests were converted into urban areas especially in the mountainous areas. As depicted in Figure 8 and Figure 9, in Koura Town where the whole is white area, the predictive value is low comparing its neighboring municipalities. In this area, since farm villages have gradually expanded around old urban areas, both old and new urban areas are mixed.

Thus we can say that the urbanization prediction model developed in this study is useful for prediction only 


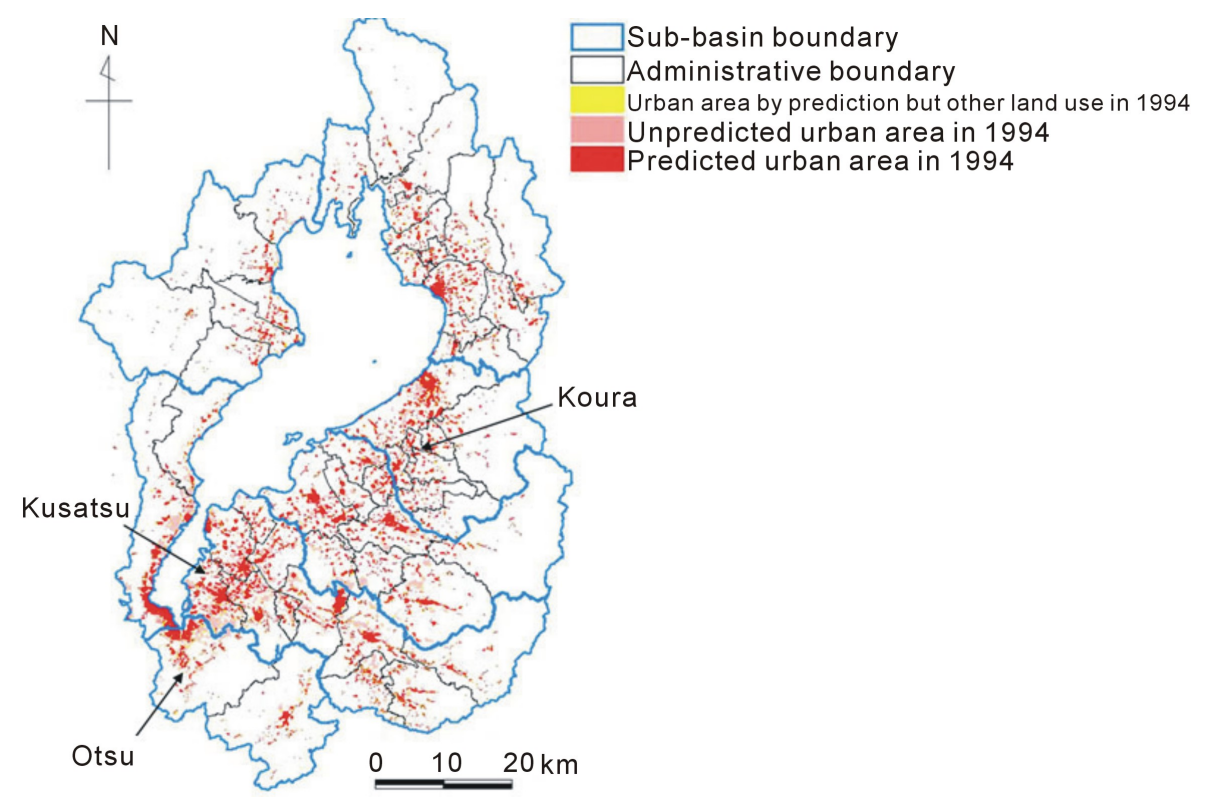

Figure 9. Urbanization prediction results compared with actual distribution of urban areas in 1994.

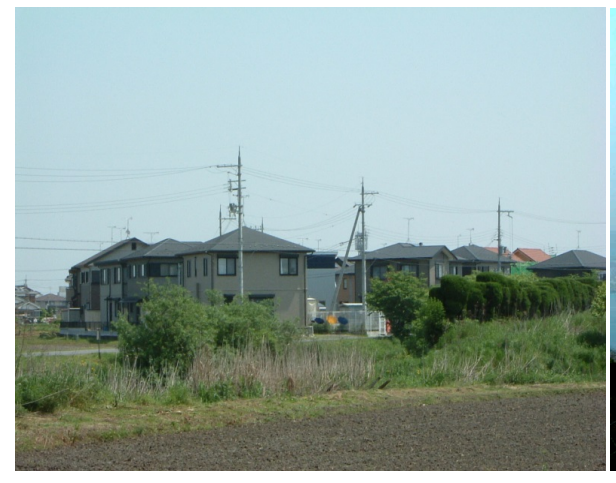

(1)

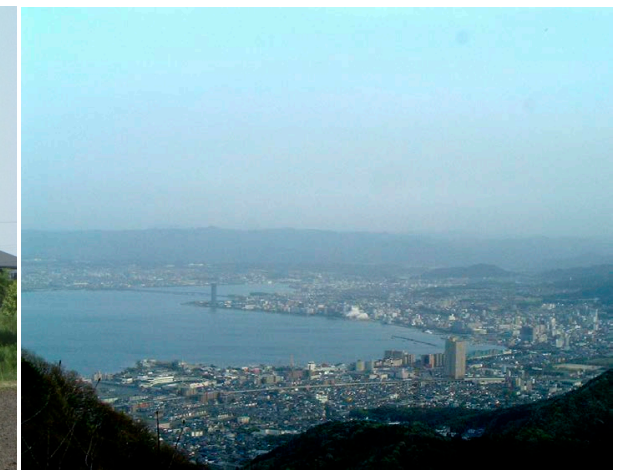

(2)

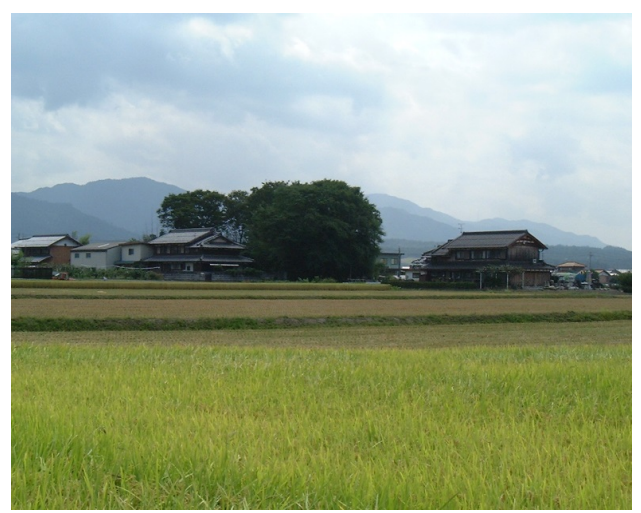

(3)

Figure 10. A part of new towns in Kusatsu city (1), high density urban areas in Otsu city (2) and a farm village in Koura town (3).

for urbanization that takes the form of urban areas diffusing around an old urban area. There are limits as to its predictive usefulness regarding intensive urbanization in areas distant from old urban areas, such as new towns 
development.

\subsection{Future Urbanization Prediction}

Assuming that urbanization during 1994-2023 advances under the same sort of conditions as during 1965-1994, further urbanization prediction for the period from 1994 to 2023 was then conducted based on the land use data taken in 1994.Because it was possible to acquire the land use data just in 1965 and 1994 from a GIS database developed for the LBCCP in Shiga Prefecture.

According to the urbanization prediction model developed in this study, the proportion of the urban area out of the total area of Shiga Prefecture will increase by about $1.3 \%$, and about $0.8 \%$ of farmlands and $0.3 \%$ of forests will be converted into urban areas and decrease respectively. In most of the areas, it was predicted that land use transformation would mainly occur with farmlands becoming urban areas. However, the land area of urban area that will be converted from forests is only about $1 \%$ out of all of the cities and towns.

Figure 11 shows the proportion by which urban areas are seen as likely to increase during 1994-2023 over what they were in 1994, per municipality. On the basis of Figure 11, the proportion of increased urban areas during 1994-2023 will be more than $115 \%$ in relatively numerous cities and towns in the southeastern part of the prefecture, and less than $110 \%$ in some cities and towns in the eastern and northern parts. Figure 12 shows the relationship between the increased urban areas in 1994-2023 and the land use controls. From Figure 12, the increased urban areas in 1994-2023 will distribute especially in the urbanization control area of southeastern parts.

From the above, if urbanization during 1994-2023 advances under the same sort of conditions as during 1965-1994, we can predict that up until 2023 it will be farmlands that decrease rather than forests and land put to other uses. Therefore, attention should be given to the necessity of adopting a mitigation system for reducing the load on Lake Biwa that will increase with future urbanization, in addition to the refurbishment of Shiga Prefecture's legal systems to protect farmlands. Particularly in the southern part of the prefecture, where the increase in urban areas during 1994-2023 looks set to be remarkable, there is a strong necessity for these things.

\section{Application of Urbanization Prediction Model to the Evaluation of Land Use Controls}

\subsection{Evaluation in Urbanization Control Areas and White Areas}

By comparing the prediction result in 1994 based on land use data in 1965 and the land use plan, an examination can be made of the effectiveness of present land use controls in urbanization control areas and white areas. In urbanization control areas and white areas, development activity is restricted and yet the reduction of farmlands and forests with the expansion of urban areas has become a serious land use problem.

As of 1994 the proportion of urban area to total land area is roughly $10 \%$ in urbanization control areas and about $8 \%$ in white areas. However, of these urban areas about $4 \%$ in urbanization control areas and about $3 \%$ in white areas are areas where urbanization had not been predicted. For urbanization control areas and white areas where the advance of urbanization must be prevented, grasping the distribution of unpredicted urban areas will make possible an examination of the problem of urbanization that advances in intensive fashion in areas that are distant from old urban areas.

Figure 13 and Figure 14 show the proportion of unpredicted urban areas in urbanization control areas and white areas respectively in 1994, per municipality. In Figure 13 we can see that although the proportion of urban areas not predicted in urbanization control areas is less than $5 \%$ in most cities and towns, it is strikingly high, more than 50\%, in four cities and two towns in the southern part of the prefecture. In Figure 14 we can see that the proportion of urban areas not predicted in white areas is more than $30 \%$ in six towns in the eastern part and five towns in the northwestern part of the prefecture.

From this we can conclude that most of the urban areas that increased over the past 30 years in urbanization control areas in the southern part and in white areas in the eastern and northwestern parts expanded in areas distant from old urban areas, and this is where the problems in land use controls arise. Moreover, since the expansion of such urban areas may give even more environmental load than foreseen to the water quality of Lake Biwa, it will be necessary to consider this point for LBCCP and in land use plans.

\subsection{Evaluation in Urbanization Promotion Area and Land Use District}

A comparison of the prediction results for the period 1994-2023 based on land use data in 1994 and land use 


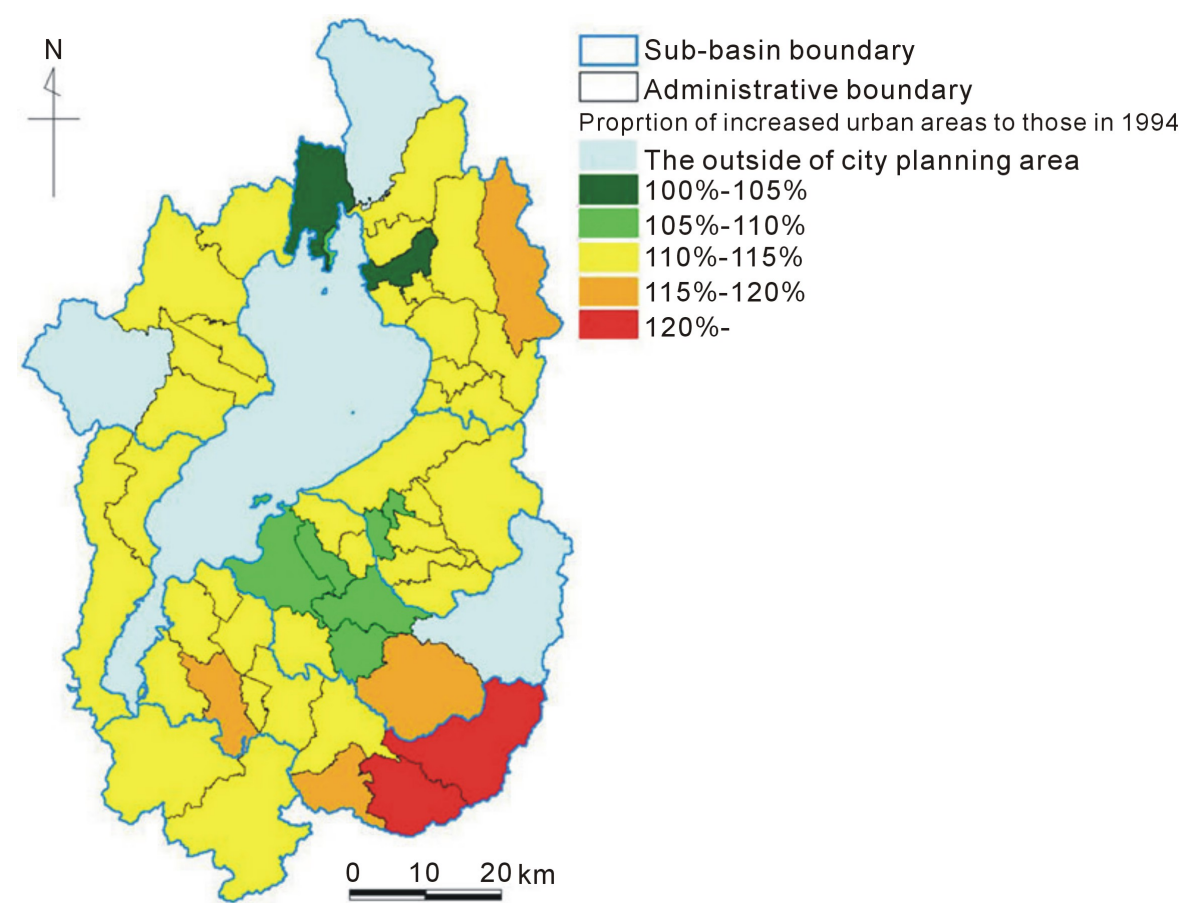

Figure 11. Propotion of increased urban areas in 1994-2023 as against 1994.

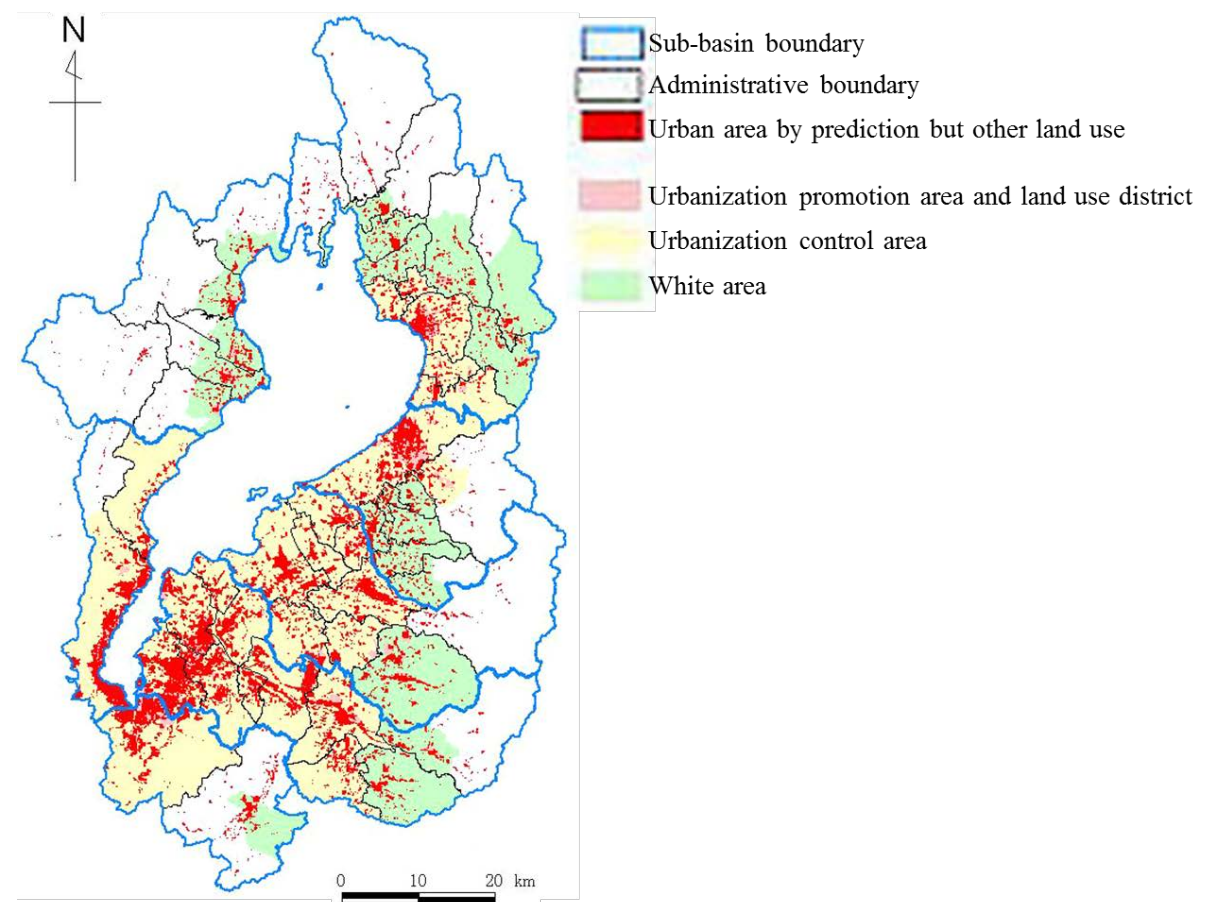

Figure 12. The relationship between the increased urban areas in 1994-2023 and the land use controls.

plans enables an examination to be made of the present land use controls in the urbanization promotion areas and the land use districts. Assuming that urbanization during 1994-2023 advances under the same sort of conditions as during 1965-1994, we can then consider whether the urbanization promotion areas and the land use districts have been designated appropriately. 


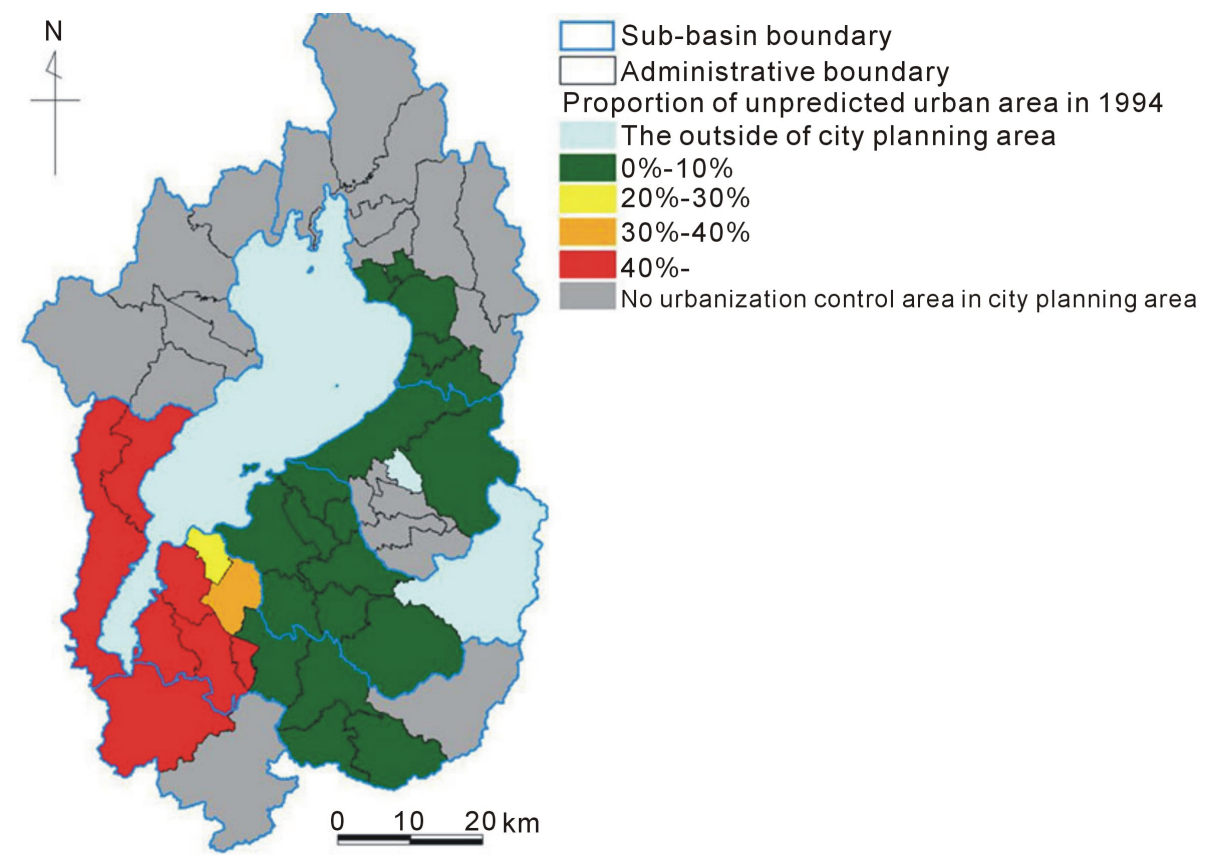

Figure 13. Unpredicted urban area in urbanization control areas in 1994.

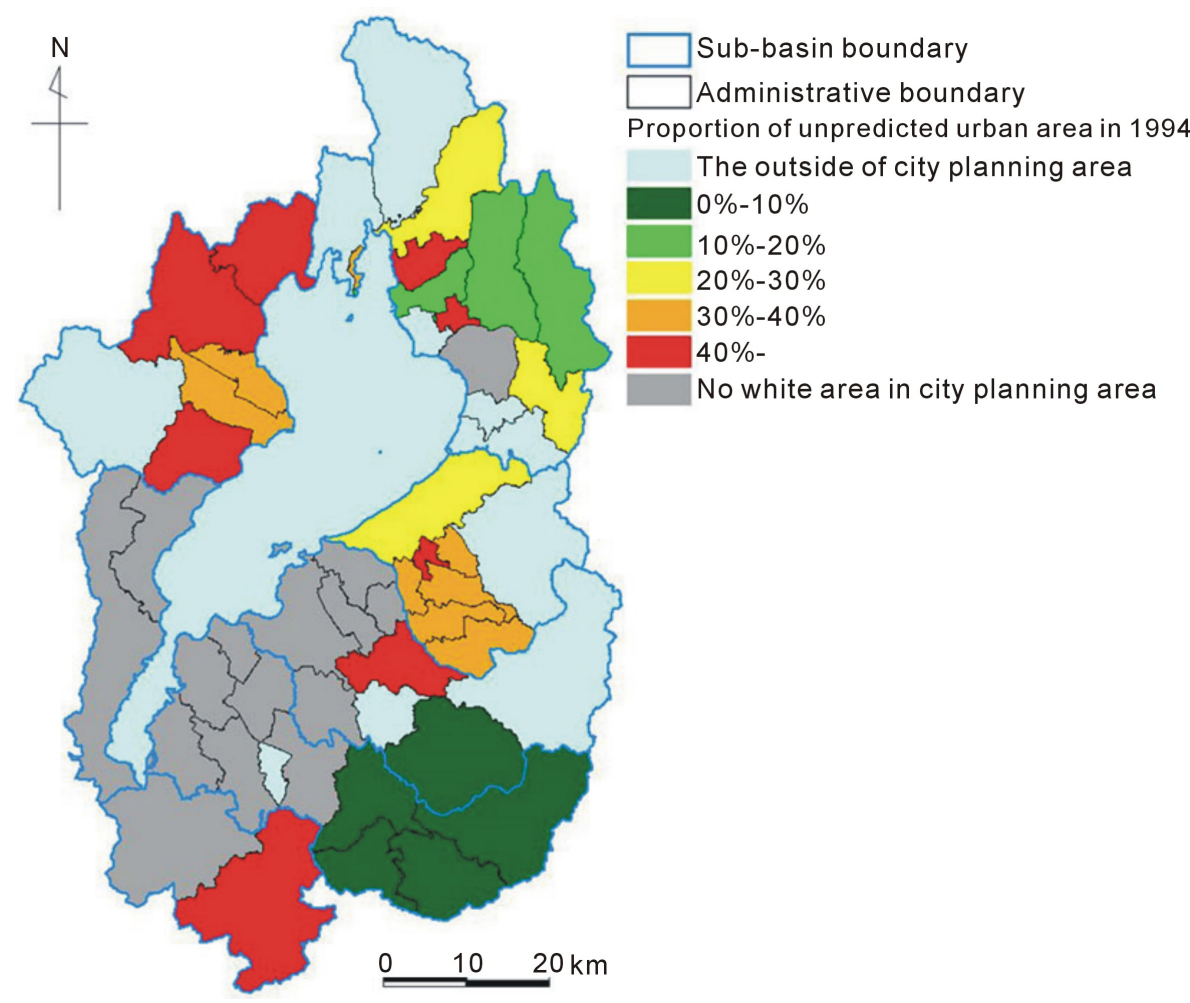

Figure 14. Unpredicted urban areas in white areas in 1994.

The prediction results show that the proportion of urban area throughout Shiga Prefecture taken as a whole will probably increase by about 6\% during 1994-2023, which for urbanization control areas and land use districts will mean an increase to about $81 \%$. Figure 15 shows the proportion of urbanization in urbanization promotion areas and land use districts during 1994-2023 based on these urbanization prediction results: we can see 


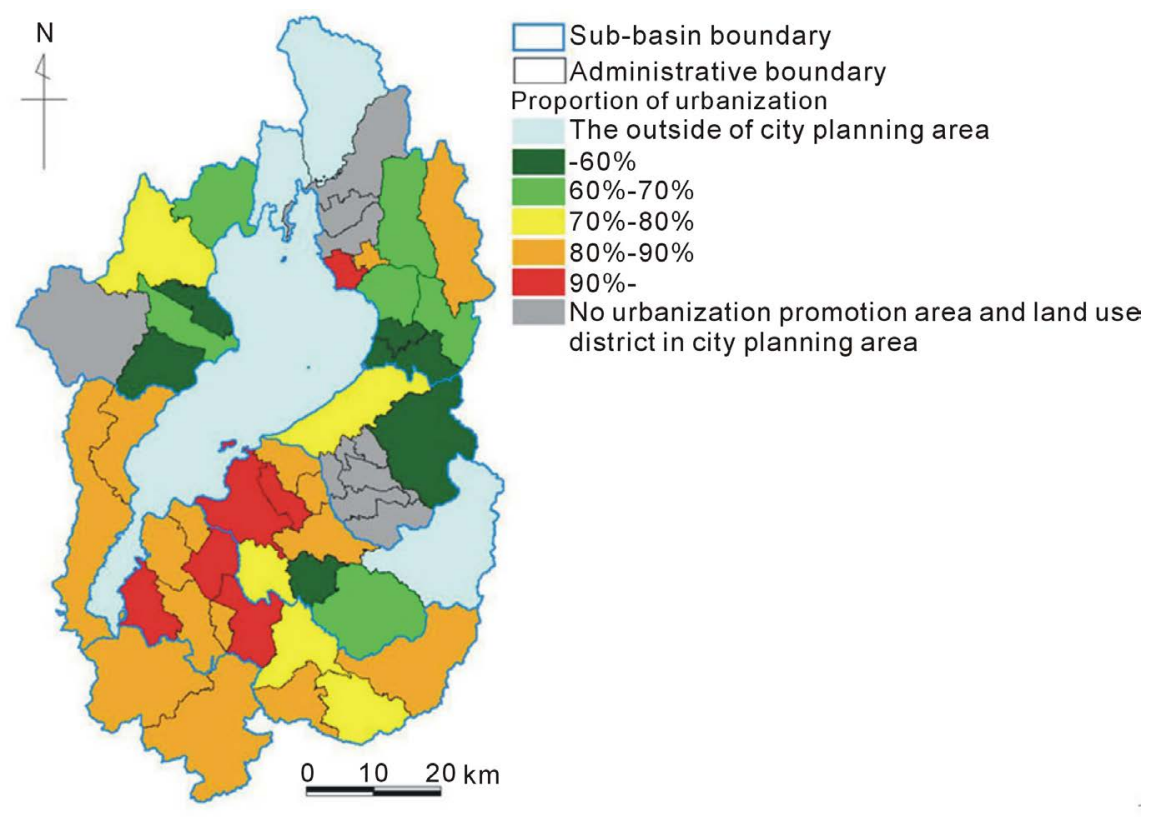

Figure 15. Prediction of proportion of urbanization in urbanization promotion areas and land use districts during 1994-2023.

that it is only in cities and towns in the southern areas that the proportion of urban area in urbanization control areas and land use districts will increase to more than $90 \%$; the proportion of urban area will remain less than $50 \%$ in small-scale towns in the northeast part. Moreover, in most small-scale towns, even if urban area does increase as predicted, the proportion of urban area in urbanization promotion areas and the land use districts will remain less than 70\%. From this, it can be said that in Shiga Prefecture in all but the southern and southeastern parts that adjoin the central part of the Keihanshin metropolitan area where urbanization can be expected to keep advancing, there are many cities and town where excessive designation has taken place of urbanization promotion areas and land use districts.

In addition, assuming that urbanization during 1994-2023 advances under the same sort of conditions as during 1965-1994, a similar comparison was also made of the urbanization prediction results for 1994-2023 and land use controls in urbanization control areas and white areas. It was found that in the urbanization control areas, the proportion of urban area will probably increase by $1.6 \%$ throughout Shiga Prefecture as a whole, while the proportion for the area taken up by actual cities and towns will probably be less than $5 \%$. Similarly the proportion of urban area will probably increase by $1.2 \%$ throughout Shiga Prefecture as a whole in the white areas after 1994, and the proportion of urban area for cities and towns will be less than $4 \%$. This suggests that there is little likelihood that urbanization will advance on a large scale in urbanization control areas and white areas purely through urban area diffusion during 1994-2023.

\section{Conclusion and Future Research}

This study aimed to develop an urbanization prediction model using the level of the block, and using the results obtained in this model in order to evaluate the present land use controls in Shiga Prefecture as a region that bordered the Keihanshin metropolitan area. In this study, GIS was used as an effective tool for the spatial analysis of land use controls, providing accurate and useful information for land use plan in Shiga Prefecture. Because GIS has only recently begun to be used in land use control assessments, it has not been possible to easily grasp land use transformations within the context of an entire region. As noted in this study, however, the use of GIS analysis has made it possible to examine land use controls on the district level, and to show analytical results as well as the distribution of the problem areas in various spatial scales on the digital maps.

By introducing GIS techniques into land use planning efforts, it is now possible to offer more valuable and useful information for developing appropriate land use policies. Through improved GIS software and interfaces, the introduction of GIS should also enhance public planning efforts. The use of GIS represents a particular pow- 
erful tool to analyze and support land use plans.

The findings of this study can be summarized as follows:

1) There have been significant land-use transformations in Shiga Prefecture over the past decades, particularly in connection with the implementation of infrastructure development projects within the Lake Biwa Comprehensive Development Plan (1972-1997). Urbanization has advanced rapidly in the plains of the southeastern parts of Shiga Prefecture, rather than in the area neighboring the Keihanshin metropolitan area. In the Urbanization Control Areas and the White Areas, the expansion of urban areas also has resulted in land use problems, which are especially serious in the wide area of the eastern part of Shiga Prefecture.

2) The predictive value of the urbanization prediction model developed in this study was $58.7 \%$ for the study area in its entirety, and in northern areas where urbanization is less advanced more than $80 \%$.

However, while this model does basically enable predictions regarding the phenomenon of diffusion in urban areas, there are limits to its suitability for predictions regarding intensive urbanization in regions distant from old urban areas.

3) Comparison of the urbanization prediction results with present land use controls revealed that many of the urban areas that expanded in the last 30 years in urbanization control areas and white areas occurred in concentrated fashion in areas that were distant from old urban areas. However, these areas are the areas where urbanization should be restricted.

Further, the urbanization prediction results also indicate that an excessive designation of urbanization promotion areas and land use districts has taken place in every area apart from areas in the south conveniently located to the center of the Keihanshin Metropolitan Area. These are areas where urban area management should be promoted in planned fashion.

In future research, it will be necessary to develop an urbanization prediction model that can take into consideration various other factors pertaining to urban conglomerations including regional traffic conditions, land use controls, and geographical conditions, regarding the plains in the southern area of Shiga Prefecture where expansion of urban areas cannot be explained only by urban diffusion. Also, in this study, restrictions in the GIS database meant that use could only be made of the two time frames of the existing digital data for an interval for 30 years. However, if and when an urbanization prediction model can be developed that will take into consideration the conditions mentioned above, it will be necessary to devise a model with a much greater level of accuracy, using for example digital data taken at ten-year intervals at three points in time.

\section{References}

[1] Yamamoto, K. (1999) A Study on the Land Use Changes on the Basin of Lake Biwa in Shiga Prefecture. Papers on Environmental Information Science, 13, 239-244. (in Japanese)

[2] Yamamoto, K. and Nakamura, M. (2000) Land-Use GIS Study for Environmental Conservation of Lake Biwa. The 4th International Conference on Integrating Geographic Information Systems (GIS) and Environmental Modeling, Banff, September 2-8, 2000. http://www.colorado.edu/research/cires/banff/pubpapers/135/

[3] Yamamoto, K. (2001) An Examination of Land Use Plan from the Viewpoint of Urban Area on the Shore of Lake Biwa in Shiga Prefecture. Journal of the Japanese Institute of Landscape Architecture, 64, 797-800. (in Japanese)

[4] Yamamoto, K. (2002) An Examination of Land Use Control from the Viewpoint of Urbanization in the Marginal Region of Metropolitan Area: A Case Study of Lake Biwa’s Drainage Basin. City Planning Review, 235, 65-76. (in Japanese) http://dx.doi.org/10.5632/jila.64.797

[5] Yamamoto, K. (2003a) An Evaluation of Land Use Controls in the Land Use Master Plan in Lake Biwa's Drainage Basin from the Viewpoint of Urbanization. Journal of the Japanese Institute of Landscape Architecture, 66, 883-888. (in Japanese) http://dx.doi.org/10.5632/jila.66.883

[6] Yamamoto, K. (2003b) An Examination of Land Use Plan by Considering the Accessibility to Traffic Facilities in the Marginal Region of Metropolitan Area: A Case Study of Lake Biwa’s Drainage Basin. Environmental Information Science, 32, 43-55. (in Japanese)

[7] Yamamoto, K. and Nakamura, M. (2004) An Examination of Land Use Controls in the Lake Biwa Watershed from the Perspective of Environmental Conservation and Management. Lakes \& Reservoirs: Research and Management, 25, 217-228. http://dx.doi.org/10.1111/j.1440-1770.2004.00251.x

[8] Yamamoto, K. (2005) Developing a GIS-Based Urbanization Prediction Method that takes into Account Neighborhood Relationship of the Unit of the "Block": A Look at the Environs of the Keihanshin Metropolitan Area in Japan. AutoCarto Proceedings Papers 2005, 19 p.

[9] Shiga Prefecture (2000) Mother Lake 21 Plan—Lake Biwa Comprehensive Conservation Plan. 65 p. (in Japanese). 
Scientific Research Publishing (SCIRP) is one of the largest Open Access journal publishers. It is currently publishing more than 200 open access, online, peer-reviewed journals covering a wide range of academic disciplines. SCIRP serves the worldwide academic communities and contributes to the progress and application of science with its publication.

Other selected journals from SCIRP are listed as below. Submit your manuscript to us via either submit@scirp.org or Online Submission Portal.
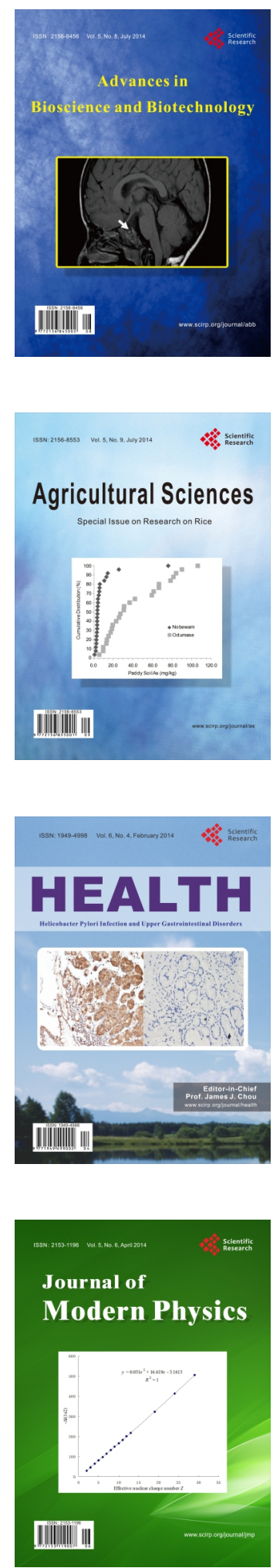
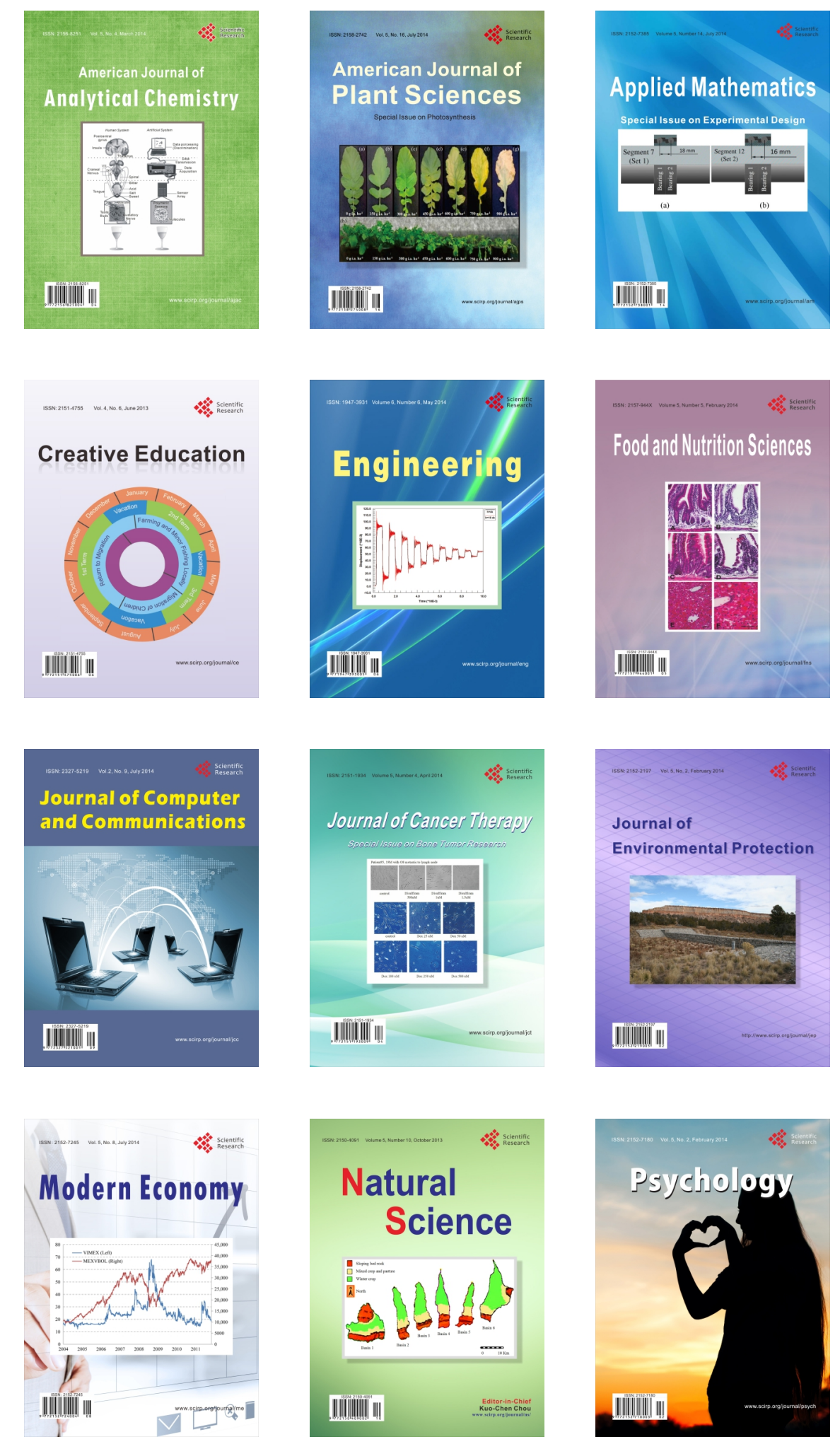